\title{
Crescimento alométrico de osso, músculo e gordura em cortes da carcaça de cordeiros Texel segundo os métodos de alimentação e peso de abate
}

\author{
Muscle, fat and bone allometric growth in Texel lambs carcasses cuts in \\ relation to the feeding methods and slaughter weight
}

\author{
Gilberto Teixeira da Rosa ${ }^{1}$ Cleber Cassol Pires ${ }^{2}$ \\ José Henrique Sousa da Silva ${ }^{3}$ Otacílio Silva da Motta ${ }^{4}$
}

\section{RESUMO}

O experimento teve como objetivo estudar o crescimento alométrico dos diferentes tecidos do pescoço, costela, paleta e perna em relação ao peso do corte de cordeiros e cordeiras. Foram utilizados 22 machos inteiros e 23 fêmeas da raça Texel. Desses, sete foram abatidos no início do experimento e os demais, aos pesos de 25 ou $33 \mathrm{~kg}$. As ovelhas mais cordeiros foram distribuídos em três métodos de alimentação: M1 -Silagem de milho e concentrado, apenas aos cordeiros até o desmame, aos 60 dias; M2 - Silagem de milho e concentrado, apenas aos cordeiros até o desmame, aos 45 dias e M3 - Silagem de milho e concentrado para ovelha mais cordeiro até o desmame com 60 dias. Após o desmame, os cordeiros receberam silagem mais concentrado. Foi utilizado um delineamento inteiramente casualizado em arranjo fatorial $3 \times 2 \times 2$ (3 métodos, 2 sexos e 2 pesos de abate). A determinação do crescimento foi obtida através da equação $\log y=\log . a+b \log . x$, utilizando-se o logaritmo do peso de osso, músculo e gordura em função do logaritmo do peso do corte. Observou-se que o osso do pescoço e da costela foram precoce $(b<1)$ em ambos os sexos, com coeficientes de alometria variando de 0,61 a 0,79; 0,81 a 0,88. O músculo foi isométrico $(b=1)$ no pescoço e precoce $(b<1)$ na costela com exceção dos machos do método um e três que apresentaram crescimento isométrico $(b=1)$. A gordura foi tardia $(b>1)$ independente de sexo e método de alimentação com coeficientes de alometria variando de 1,78 a 2,15 (pescoço) e 1,51 a 1,65 (costela). Na paleta, o osso foi precoce em ambos os sexos, com coeficientes de alometria variando de 0,76 a 0,79 e 0,54 a 0,58 respectivamente para machos $e$ fêmeas. $O$ músculo apresentou crescimento isométrico $(b=1)$, independente de sexo e peso de abate. A gordura foi tardia $(b>1)$ independente de peso de abate e sexo, com coeficientes de alometria variando de 1,80 a 2,12. Na perna o osso apresentou crescimento precoce nas fêmeas $e$ isométricas nos machos, com coeficientes de alometria variando de 0,57 a 0,63 e 0,78 a 0,80 respectivamente para ambos os sexos $O$ músculo apresentou crescimento isométrico $(b=1)$, independente de sexo e peso de abate. A gordura foi tardia $(b>1)$ independente de peso de abate e sexo com coeficientes de alometria variando de 1,80 a 2,12.

Palavras-chave: coeficientes alométricos, ovinos e sexo.

\section{ABSTRACT}

The experiment aimed at studying the allometric growth of the different tissues of neck, rib, shoulder blade and leg in relation to the cutting weight of male and female lambs. Twenty-two intact Texel males and 23 Texel females were used. Seven of them were slaughtered at the beginning of the experiment and the others at the weight of 25 or $33 \mathrm{~kg}$. Sheep and lambs were distributed into three methods of feeding: M1 - Corn silage and concentrate, only to lambs until weaning at 60 days old; M2 - Corn silage and concentrate, only to lambs until weaning at 45 days old and M3 - Corn silage and concentrate to ewe and lamb until weaning at 60 days old. After weaning, lambs were fed with silage plus concentrate. A completely randomized design outlined in a factorial arrangement $3 \times 2 \times 2$ (3 methods, 2 sexes and 2 slaughter weights) was used. Determination of growth was obtained through the equation log $y=\log . a+b$ log.x, by using the logarithm of bone, muscle and fat weight in function of cutting weight logarithm. It was observed that neck and rib bone was precocious $(b<1)$ in both sexes, with allometry coefficients varying from 0.61 to $0.79 ; 0.81$ to 0.88. Muscle was isometric $(b=1)$ in neck and precocious $(b<1)$ in rib, except for males of methods one and three, which presented isometric growth $(b=1)$. Fat was late $(b>1)$, regardless of sex and feeding method with allometry coefficients varying from 1.78 to 2.15 (neck) and 1.51 to

'Programa Pós-graduação em Zootecnia, área de Nutrição e Produção Animal, Universidade Estadual Paulista (Unesp). E-mail: gtr@fca.unesp.br, Rua Camilo Mazone, 850, bairro Jardim Paraíso, 18610-460, Botucatu, SP, Brasil. 014-3814-2856. Autor para correspondência.

2Departamento de Zootecnia, Universidade Federal de Santa Maria (UFSM), Santa Maria, RS, Brasil. E-mail: cpires@ccr.ufsm.br. ${ }^{3}$ Departamento de Zootecnia na UFSM, Santa Maria, RS, Brasil. E-mail. jhen@ccr.ufsm.br.

${ }^{4}$ Escola Agrotécnica Federal de Alegrete, Alegrete, RS, Brasil. 
1.65 (rib). In shoulder blade, bone was precocious in both sexes, with allometry coefficients varying from 0.76 to 0.79 and 0.54 to 0.58 for males and females, respectively. Muscle presented isometric growth $(b=1)$, regardless of sex and slaughter weight. Fat was late $(b>1)$, regardless of slaughter weight and sex, with allometry coefficients varying from 1.80 to 2.12. In leg, bone growth was precocious in females and isometric in males, with allometry coefficients varying from 0.57 to 0.63 and 0.78 to 0.80 , respectively, for both sexes. Muscle presented isometric growth $(b=1)$, regardless of sex and slaughter weight. Fat was late $(b>1)$, regardless of slaughter weight and sex, with allometry coefficients varying from 1.80 to 2.12 .

Key words: allometric coefficients, sheep e sex.

\section{INTRODUÇÃO}

Crescimento é o aumento de peso e tamanho até que o animal alcance a maturidade (HAMMOND, 1966). Para OWEN (1976), crescimento e desenvolvimento descrevem a fase de mudança entre a concepção e a maturidade, sendo que a taxa e a qualidade deste processo ocorre normalmente, se ao animal forem oferecidas boas condições de alimentação da concepção à maturidade. GRAHAM (1982) define, sob um ponto de vista bioquímico, como ocorre o predomínio da síntese protéica sobre a degradação de quase todos os tecidos orgânicos simultaneamente, representado pela diferença entre o que se constrói (anabolismo) e o que se destrói (catabolismo) e por um sistema biológico definido como um acréscimo de matéria, o qual é medido pelo aumento do tamanho das células e pelo acúmulo de substâncias extracelulares. SOBRERO (1986) diz que crescimento é uma forma de produzir carne, que começa na concepção e termina na maturidade, quando cessa o crescimento em tamanho.

Os machos possuem ossos mais grossos que as fêmeas, e os ossos dos animais de raça modernas, melhoradas para a produção de carne, são mais curtos e mais grossos, em relação a animais não melhorados (HAFEZ, 1972). WYNN \& THWAITES (1981), trabalhando com cordeiros da raça Merina puros e cruzada (Border Leicester x Merina), observaram que os animais cruzados possuem maior quantidade de osso do que os animais puros quando comparados aos pesos de abate de $10 ; 40$ e $50 \mathrm{~kg}$ de peso vivo.

O crescimento do tecido muscular é caracterizado, até o nascimento, pelo aumento do número de células e, após o nascimento, pelo aumento do tamanho das células. De acordo com BERG \& BUTTERFIELD (1976), o crescimento diferencial que ocorre entre os diversos músculos, acontece em fases: $1^{a}$ ) na fase pré-natal, os músculos estão estimulados pela tenção passiva, motivados pelo crescimento do esqueleto; $2^{\underline{a}}$ ) na fase pós-natal imediata, ocorre grande mudança no peso relativo da musculatura, que está em parte influenciado pelas funções do músculo; $3^{\text {a })}$ na fase pré-puberal a adolescência, os músculos crescem a uma velocidade uniforme e há um grande aumento em tamanho, mas com pouca mudança no peso relativo; $4^{\mathrm{a}}$ ) na fase de terminações, ocorre um aumento da proporção relativa da musculatura do macho inteiro, em relação ao castrado e é caracterizada pela constância na liberação de hormônios androgênicos, sendo que os machos castrados apresentam pequena alteração na musculatura, provavelmente devido à deficiência na produção a liberação desses hormônios.

A gordura é o tecido de maior variabilidade no animal, seja do ponto de vista quantitativo ou por sua distribuição e a função biológica fundamental do tecido adiposo é o armazenamento de energia para os períodos de escassez alimentar, caso das épocas de seca e inverno. O tecido adiposo tem papel fundamental nas diferenças de composição corporal entre touros, machos castrados e fêmeas. As fêmeas iniciam a depositar gordura com pesos menores do que os machos castrados e touros, e os machos castrados a pesos menores do que os inteiros (HAFEZ, 1972). Para HAMMOND (1959), cada espécie e cada raça têm um padrão característico de deposição de gordura. Ao nascimento, está presente uma pequena proporção de gordura e à medida que o animal cresce aumenta a deposição, tanto por hipertrofia, como por hiperplasia. Este experimento objetivou estudar o crescimento de osso, músculo e gordura do pescoço, costela, paleta e perna em relação ao peso do corte de cordeiros (as) sob diferentes métodos de alimentação e desmamados aos 45 ou 60 dias.

\section{MATERIAL E MÉTODOS}

O trabalho foi realizado no Setor de Ovinocultura do Departamento de Zootecnia da Universidade Federal de Santa Maria, RS, utilizando 45 cordeiros (22) machos não castrados e (23) fêmeas da raça Texel. Desses, abateram-se sete animais no início do experimento 24 horas após o nascimento e os demais assim que atingiam os pesos de 25 ou $33 \mathrm{~kg}$. Os cordeiros remanescentes foram distribuídos, aleatoriamente, 24 horas após o nascimento, com suas respectivas mães, em três métodos de alimentação: M1- Alimentação com silagem de milho para cordeiro + ovelha, com fornecimento de concentrado apenas aos cordeiros na forma de creep feeding do nascimento ao desmame, aos 60 dias de idade, M2- Alimentação 
com silagem de milho para cordeiro + ovelha, com fornecimento de concentrado apenas aos cordeiros na forma de creep feeding, do nascimento ao desmame aos 45 dias de idade e M3- Alimentação com silagem de milho + concentrado com uma proporção de 70:30 na matéria seca (MS) para o conjunto ovelha mais cordeiro do nascimento ao desmame aos 60 dias de idade.

Todos os cordeiros eram oriundos de parto simples, sendo o M1 e M3 constituídos de 13 cordeiros (7 machos e 6 fêmeas) e o M2 de 12 cordeiros (6 machos e 6 fêmeas). No abate, para cada peso vivo proposto, manteve-se a proporção de $50 \%$ machos e $50 \%$ fêmeas. Os cordeiros, em cada método de alimentação, foram alimentados num galpão coberto com telha de amianto em baias coletivas com piso revestido de cimento. Após o desmame, cada lote de cordeiro permaneceu em suas baias recebendo uma dieta contendo $16,7 \%$ de PB e $69,4 \%$ de NDT, formulada a partir de silagem de milho e um concentrado composto de milho desintegrado, farelo de soja, fosfato bicálcico, calcário calcítico e sal comum numa proporção de volumoso:concentrado de 50:50 na matéria seca. Foi adotado um delineamento inteiramente casualizado em arranjo fatorial $3 \times 2 \times 2$ (3 métodos, 2 sexos e 2 pesos de abate).

Após o abate, a carcaça foi resfriada por 24 horas a uma temperatura de $2^{\circ} \mathrm{C}$ e, logo após, dividida através de um corte longitudinal iniciado na sínfese ísquio-pubiana e finalizado na última vértebra cervical, obtendo-se, assim, metades aproximadamente simétricas. Na meia carcaça esquerda, foi realizadas a separação do pescoço, paleta, costela e perna, os quais foram pesados separadamente. $\mathrm{O}$ corte do pescoço foi feito entre a 7 a e 8 a vértebra cervical. A costela foi seccionada entre a última vértebra cervical e a primeira torácica e a última lombar e a primeira sacral; o corte da paleta foi obtido liberando-se a escápula da costela e, na porção média dos ossos do carpo e a perna, foi seccionada na articulação da última vértebra lombar e primeira sacral e na porção média dos ossos do tarso. Paleta, costela, perna e pescoço foram dissecados para se obter as quantidades de osso, músculo e gordura. As análises estatísticas foram realizadas no Núcleo de Processamento de Dados da UFSM, através do programa estatístico SAS (SAS, 1996). A determinação do crescimento foi realizada através da equação exponencial $\mathrm{y}=\mathrm{ax}^{\mathrm{b}}$, de HUXLEY (1932) transformada logaritmicamente em $\log y=\log$ $\mathrm{a}+\mathrm{b} \log \mathrm{x}$, sendo que: $\mathrm{y}=$ peso de osso, músculo e gordura de cada corte: paleta, costela, perna e pescoço. "a" é a intercepção do logaritmo da regressão linear sobre y e "b" o coeficiente de crescimento relativo ou coeficiente de alometria e " $x$ " o peso do corte. Para verificação da hipótese $b=1$, foi utilizado o teste " $t$ " (Student), com nível de significância de $(\mathrm{P}<0,05)$. Se $\mathrm{b}=1$, o crescimento foi denominado isogônico, indicando que as taxas de crescimento de "X" e "Y" foram semelhantes no intervalo considerado. Quando $b \neq 1$, o crescimento é heterogônico, sendo precoce se $\mathrm{b}<1$ e tardio se $\mathrm{b}>1$.

\section{RESULTADOS E DISCUSSÃO}

Nas tabelas 1 e 2, estão apresentados os coeficientes de alometria para osso, músculo e gordura da costela e pescoço respectivamente, para machos e fêmeas obtidos através da regressão do logaritmo do peso de cada tecido, em função do peso do corte. Os resultados indicam que o osso apresentou crescimento precoce em ambos os cortes $(b<1)$ e o tecido adiposo tardio ( $>>1$ ) para machos e fêmeas. O músculo da costela apresentou desenvolvimento isométrico $(b=1)$, nos machos do M2 e M3, isto é, crescendo com a mesma velocidade do corte e precoce $(b<1)$ nos demais. No pescoço foi precoce $(b<1)$ nas fêmeas do M2 e M3 e isométrico (b1) nos demais. Estes resultados de um modo geral, são concordantes com WOOD et al. (1980) que descreveram crescimento precoce para todos os tecidos do pescoço, e precoce, isométrico e tardio para o tecido ósseo, muscular e adiposo da costela, respectivamente. Os autores também citaram que o desenvolvimento dos tecidos do pescoço é maior nos machos que nas fêmeas.

SANTOS (1999), estudando o crescimento da costela e costela fralda de cordeiros Santa Inês e Bergamácia abatidos aos 15; 25; 35 e $45 \mathrm{~kg}$ de peso vivo, observou para a costela, que o tecido ósseo foi de crescimento precoce $(b<1)$ e o adiposo tardio em ambas as raças respectivamente. $\mathrm{O}$ tecido muscular apresentou crescimento isométrico nos Bergamácia e tardio nos Santa Inês, demonstrando uma influencia da raça no desenvolvimento muscular da costela. Já para costela fralda, verificou crescimento precoce $(b<1)$ para o osso, isométrico no músculo $(b=1)$ e tardio na gordura $(b>1)$, nas duas raças, o que siginifica que, de um modo geral, os resultados deste experimento são concordantes com os resultados encontrados pelo referido autor. No entanto, no caso do autor citado, a costela foi dividida em dois cortes, mas permaneceu com a mesma seqüência de desenvolvimento de seus tecidos com os encontrados neste experimento. HUIDOBRO \& VILLAPADIERNA (1992), com animais abatidos aos 15; 25 e 35kg de peso vivo encontraram coeficientes de alometria para o tecido ósseo do pescoço de 1,53 (b>1), 1,05 (b=1) nos intervalos de 15 a 25 e 25 a $35 \mathrm{~kg}$ de peso vivo. Verificaram

Ciência Rural, v.35, n.4, jul-ago, 2005. 
Tabela 1 - Parâmetros estimados das equações de alometria e erro padrão para osso, músculo e gordura da costela em relação ao peso do corte de cordeiros machos (M) e fêmeas (F) submetidos a diferentes métodos de alimentação (M1, M2 e M3) e teste t (Ho:b=1).

\begin{tabular}{|c|c|c|c|c|c|c|c|}
\hline Tecidos & $\mathrm{S}$ & M & $\mathrm{a}$ & $\mathrm{b}$ & seb & Teste $\mathrm{t}$ & $\mathrm{r}^{2}$ \\
\hline Osso & $\mathrm{M}$ & 1 & $-0,106857$ & 0,817737 & 0,035 & $*$ & 98,71 \\
\hline Osso & $\mathrm{F}$ & 1 & $-0,295310$ & 0,855566 & 0,025 & $*$ & 99,36 \\
\hline Osso & M & 2 & $-0,088672$ & 0,810493 & 0,032 & $*$ & 98,75 \\
\hline Osso & $\mathrm{F}$ & 2 & $-0,355530$ & 0,883569 & 0,028 & $*$ & 99,16 \\
\hline Osso & M & 3 & $-0,170456$ & 0,846147 & 0,034 & $*$ & 98,72 \\
\hline Osso & $\mathrm{F}$ & 3 & $-0,358765$ & 0,884019 & 0,020 & $*$ & 99,57 \\
\hline Músculo & M & 1 & $-0,027671$ & 0,929157 & 0,027 & $*$ & 99,39 \\
\hline Músculo & $\mathrm{F}$ & 1 & 0,043257 & 0,921802 & 0,010 & $*$ & 99,91 \\
\hline Músculo & M & 2 & $-0,129410$ & 0,944773 & 0,020 & NS & 99,66 \\
\hline Músculo & $\mathrm{F}$ & 2 & 0,077750 & 0,906508 & 0,015 & $*$ & 99,77 \\
\hline Músculo & $\mathrm{M}$ & 3 & $-0,052912$ & 0,941313 & 0,027 & NS & 99,30 \\
\hline Músculo & $\mathrm{F}$ & 3 & 0,150308 & 0,873887 & 0,022 & $*$ & 99,46 \\
\hline Gordura & M & 1 & $-2,849349$ & 1,651336 & 0,132 & $*$ & 96,28 \\
\hline Gordura & $\mathrm{F}$ & 1 & $-2,395243$ & 1,518178 & 0,059 & $*$ & 99,40 \\
\hline Gordura & M & 2 & $-2,641559$ & 1,563192 & 0,114 & $*$ & 96,36 \\
\hline Gordura & $\mathrm{F}$ & 2 & $-2,384598$ & 1,511786 & 0,079 & $*$ & 98,63 \\
\hline Gordura & M & 3 & $-2,805392$ & 1,637142 & 0,104 & $*$ & 97,21 \\
\hline Gordura & $\mathrm{F}$ & 3 & $-2,525255$ & 1,577329 & 0,083 & $*$ & 98,61 \\
\hline
\end{tabular}

M1- Alimentação com silagem de milho para cordeiro + ovelha, com fornecimento de concentrado apenas aos cordeiros na forma de creep feeding do nascimento ao desmame, aos 60 dias de idade, M2- Alimentação com silagem de milho para cordeiro + ovelha, com fornecimento de concentrado apenas aos cordeiros na forma de creep feeding, do nascimento ao desmame aos 45 dias de idade e M3- Alimentação com silagem de milho + concentrado com uma proporção de 70:30 na matéria seca (MS) para o conjunto ovelha mais cordeiro do nascimento ao desmame aos 60 dias de idade; seb = Erro padrão; $*$ = significativo para $(\mathrm{P}=0,05) ; \mathrm{NS}=$ não significativo para $(\mathrm{P}=0,05) ; \mathrm{r}^{2}=$ Coeficiente de determinação.

Tabela 2 - Parâmetros estimados das equações de alometria e erro padrão para osso, músculo e gordura do pescoço em relação ao peso do corte de cordeiros machos (M) e fêmeas (F) submetidos a diferentes métodos de alimentação (M1, M2 e M3) e teste t (Ho:b=1).

\begin{tabular}{|c|c|c|c|c|c|c|c|}
\hline Tecidos & $\mathrm{S}$ & $\mathrm{M}$ & $\mathrm{a}$ & $\mathrm{b}$ & \multicolumn{2}{|c|}{ Teste $\mathrm{t}$} & $r^{2}$ \\
\hline Osso & $\mathrm{M}$ & 1 & 0,267722 & 0,616657 & 0,155 & $*$ & 69,29 \\
\hline Osso & $\mathrm{F}$ & 1 & $-0,026392$ & 0,734321 & 0,069 & $*$ & 94,09 \\
\hline Osso & $\mathrm{M}$ & 2 & 0,118876 & 0,700759 & 0,101 & $*$ & 85,57 \\
\hline Osso & $\mathrm{F}$ & 2 & $-0,047366$ & 0,745552 & 0,053 & $*$ & 96,10 \\
\hline Osso & $\mathrm{M}$ & 3 & $-0,210307$ & 0,655727 & 0,103 & $*$ & 83,42 \\
\hline Osso & $\mathrm{F}$ & 3 & $-0,130345$ & 0,792294 & 0,088 & NS & 90,92 \\
\hline Músculo & $\mathrm{M}$ & 1 & $-0,058114$ & 0,872567 & 0,341 & NS & 48,25 \\
\hline Músculo & $\mathrm{F}$ & 1 & $-0,087674$ & 0,930754 & 0,025 & NS & 99,47 \\
\hline Músculo & $\mathrm{M}$ & 2 & $-0,044467$ & 0,880057 & 0,330 & NS & 46,98 \\
\hline Músculo & $\mathrm{F}$ & 2 & $-0,151859$ & 0,969083 & 0,057 & $*$ & 97,30 \\
\hline Músculo & $\mathrm{M}$ & 3 & 0,015511 & 0,847817 & 0,336 & NS & 44,19 \\
\hline Músculo & $\mathrm{F}$ & 3 & 0,078640 & 0,828617 & 0,058 & $*$ & 96,13 \\
\hline Gordura & M & 1 & $-3,275029$ & 2,025892 & 0,264 & $*$ & 90,71 \\
\hline Gordura & $\mathrm{F}$ & 1 & $-2,927654$ & 1,922300 & 0,163 & $*$ & 97,18 \\
\hline Gordura & M & 2 & $-3,243347$ & 1,987877 & 0,098 & $*$ & 98,30 \\
\hline Gordura & $\mathrm{F}$ & 2 & $-2,625630$ & 1,783384 & 0,200 & $*$ & 94,03 \\
\hline Gordura & M & 3 & $-3,556712$ & 2,154763 & 0,108 & $*$ & 98,25 \\
\hline Gordura & $\mathrm{F}$ & 3 & $-3,052855$ & 2,002285 & 0,155 & $*$ & 97,06 \\
\hline
\end{tabular}

M1- Alimentação com silagem de milho para cordeiro + ovelha, com fornecimento de concentrado apenas aos cordeiros na forma de creep feeding do nascimento ao desmame, aos 60 dias de idade, M2- Alimentação com silagem de milho para cordeiro + ovelha, com fornecimento de concentrado apenas aos cordeiros na forma de creep feeding, do nascimento ao desmame aos 45 dias de idade e M3- Alimentação com silagem de milho + concentrado com uma proporção de 70:30 na matéria seca (MS) para o conjunto ovelha mais cordeiro do nascimento ao desmame aos 60 dias de idade; seb = Erro padrão; * = significativo para $(\mathrm{P}=0,05) ; \mathrm{NS}=$ não significativo para $(\mathrm{P}=0,05) ; \mathrm{r}^{2}=\mathrm{Coeficiente}$ de determinação.

Ciência Rural, v.35, n.4, jul-ago, 2005. 
que o músculo e a gordura foram de crescimento precoce e tardio com coeficientes de alometria de $0,88(b<1)(15$ a $25 \mathrm{~kg}$ ) e 1,30 (b>1) (25 a $35 \mathrm{~kg}$ ), valores próximos aos resultados deste estudo. Observaram também que a costela apresentou coeficientes de alometria de 1,41 (b>1) e 0,68 (b<1) para o osso, nos intervalos de 15 a $25 \mathrm{~kg}$ e 25 a $35 \mathrm{~kg}$ e 0,86 (b<1) para o músculo no intervalo de 15 a $35 \mathrm{~kg}$ de peso vivo. Para gordura, os autores observaram crescimento tardio no intervalo de 25 a $35 \mathrm{~kg}$ e isométrico no intervalo de 15 a $35 \mathrm{~kg}$ de peso vivo com coeficientes de alometria de 2,03 (>1) e 1,29 (b = 1) respectivamente. Taylor et al. (1989) citaram que o sexo e o sistema de criação são fatores que influenciam na produção de carcaça de qualidade sempre que o estado de maturidade ao abate for precoce e dentro da mesma raça, e igual peso de carcaça. As fêmeas apresentam carcaças com maior proporção de gordura, pois atingem a maturidade fisiológica mais cedo, sendo que os machos castrados e os inteiros apresentam maior desenvolvimento muscular.

Os coeficientes de alometria para osso, músculo e gordura da paleta, obtidos através da regressão do logaritmo do peso de cada tecido, em função do peso do corte são apresentados na tabela 3 . Os resultados mostram que o tecido ósseo foi de crescimento precoce $(b<1)$, independente de sexo e método de alimentação. Esses resultados corroboram com os encontrados por BERG \& BUTTERFIELD (1976) que concluíram que o tecido ósseo é de desenvolvimento precoce e apresenta um coeficiente de crescimento baixo. O músculo apresentou crescimento heterogônico negativo, precoce $(b<1)$ nos machos do M1 e fêmeas do M3 demonstrando influencia do sexo nestes métodos de alimentação e isogônico nos demais, sendo este um tecido que acompanha o desenvolvimento do corte e diminui a velocidade de crescimento à medida que aumenta $\mathrm{o}$ peso de abate. A gordura teve crescimento heterogônico positivo $(b>1)$ independente de sexo e peso de abate. A gordura é um tecido de crescimento tardio aumentando sua proporção com aumento da maturidade do animal, tendo como conseqüência menor eficiência alimentar.

Os resultados são concordantes com os obtidos por GARCIA (2001), que estudou o crescimento dos tecidos da paleta em função do corte em cordeiros machos e fêmeas de diferentes grupos genéticos, Santa Inês (SS), Ile de France x Santa Inês (FS), Bergamácia x Santa Inês (BS) e Texel x Santa Inês (TS) abatidos aos $15 ; 25 ; 35$ e $45 \mathrm{~kg}$, e verificou um

Tabela 3 - Parâmetros estimados das equações de alometria e erro padrão para osso, músculo e gordura da paleta em relação ao peso do corte de cordeiros machos (M) e fêmeas (F) submetidos a diferentes métodos de alimentação (M1, M2 e M3) e teste t (Ho:b=1).

\begin{tabular}{|c|c|c|c|c|c|c|c|}
\hline Tecidos & $\mathrm{S}$ & M & $\mathrm{a}$ & $\mathrm{b}$ & seb & Teste $\mathrm{t}$ & $\mathrm{r}^{2}$ \\
\hline Osso & $\mathrm{M}$ & 1 & $-0,018211$ & 0,783125 & 0,062 & $*$ & 95,68 \\
\hline Osso & $\mathrm{F}$ & 1 & 0,661834 & 0,549416 & 0,092 & $*$ & 83,41 \\
\hline Osso & M & 2 & 0,040898 & 0,762877 & 0,019 & $*$ & 99,47 \\
\hline Osso & $\mathrm{F}$ & 2 & 0,579742 & 0,586918 & 0,077 & $*$ & 87,64 \\
\hline Osso & M & 3 & $-0,034119$ & 0,796535 & 0,045 & $*$ & 97,49 \\
\hline Osso & $\mathrm{F}$ & 3 & 0,591784 & 0,580096 & 0,073 & $*$ & 88,59 \\
\hline Músculo & M & 1 & $-0,023516$ & 0,932778 & 0,024 & $*$ & 99,51 \\
\hline Músculo & $\mathrm{F}$ & 1 & $-0,141639$ & 0,984136 & 0,028 & NS & 99,42 \\
\hline Músculo & M & 2 & $-0,193986$ & 1,005823 & 0,030 & NS & 99,28 \\
\hline Músculo & $\mathrm{F}$ & 2 & $-0,100361$ & 0,964894 & 0,017 & NS & 99,73 \\
\hline Músculo & M & 3 & $-0,084368$ & 0,957301 & 0,022 & NS & 99,55 \\
\hline Músculo & $\mathrm{F}$ & 3 & $-0,045594$ & 0,939862 & 0,022 & $*$ & 99,56 \\
\hline Gordura & M & 1 & $-3,621247$ & 1,935531 & 0,123 & $*$ & 97,62 \\
\hline Gordura & $\mathrm{F}$ & 1 & $-3,678213$ & 1,960601 & 0,065 & $*$ & 99,55 \\
\hline Gordura & M & 2 & $-3,019164$ & 1,668366 & 0,216 & $*$ & 89,44 \\
\hline Gordura & $\mathrm{F}$ & 2 & $-3,533204$ & 1,889794 & 0,181 & $*$ & 95,61 \\
\hline Gordura & M & 3 & $-3,486106$ & 1,873232 & 0,104 & $*$ & 97,85 \\
\hline Gordura & $\mathrm{F}$ & 3 & $-3,623061$ & 1,938446 & 0,187 & $*$ & 95,54 \\
\hline
\end{tabular}

M1- Alimentação com silagem de milho para cordeiro + ovelha, com fornecimento de concentrado apenas aos cordeiros na forma de creep feeding do nascimento ao desmame, aos 60 dias de idade, M2- Alimentação com silagem de milho para cordeiro + ovelha, com fornecimento de concentrado apenas aos cordeiros na forma de creep feeding, do nascimento ao desmame aos 45 dias de idade e M3- Alimentação com silagem de milho + concentrado com uma proporção de 70:30 na matéria seca (MS) para o conjunto ovelha mais cordeiro do nascimento ao desmame aos 60 dias de idade; seb = Erro padrão; * = significativo para $(\mathrm{P}=0,05) ; \mathrm{NS}=$ não significativo para $(\mathrm{P}=0,05) ; \mathrm{r}^{2}=\mathrm{Coeficiente}$ de determinação.

Ciência Rural, v.35, n.4, jul-ago, 2005. 
crescimento alométrico negativo do osso da paleta $(b<1)$. O músculo de machos e fêmeas do grupo genético (BS), assim como para os machos (TS) e as fêmeas (FS), obtiveram coeficientes alométricos diferentes de um $(b<1)$, ou seja, heterogônico negativo, mostrando que, para esses grupos, o músculo possui um desenvolvimento precoce em relação ao desenvolvimento do corte. Verificou também que para os machos do grupo (SS), e (FS), e as fêmeas (SS) e (TS), o músculo cresceu de maneira semelhante em relação ao corte da paleta. O mesmo autor observou que a gordura, nas fêmeas de todas as raças e dos machos (TS), (FS) e (BS) tiveram um crescimento heterogônico positivo ( $\mathrm{b}>1)$, mas nos machos (SS) o crescimento foi isométrico $(b=1)$. Isso deve-se aos animais da raça Santa Inês apresentarem uma menor deposição de gordura na carcaça. Resultados do presente trabalho corroboram os de SANTOS (1999), com cordeiros da raça Santa Inês e Bergamácia, que observou crescimento heterogônico negativo $(b<1)$, isométrico $(b=1)$ e heterogônico positivo $(b>1)$ para osso, músculo e gordura respectivamente. HUIDOBRO \& VILLAPADIERNA (1992) constataram coeficientes de alometria de $0,76(b<1)$ para osso, 1,20 (b>1) para músculo e 2,28 (b>1) para gordura da paleta em cordeiros abatidos aos 15; 25 e $35 \mathrm{~kg}$ de peso vivo. Os referidos autores observaram um maior crescimento muscular no intervalo de 15 a $25 \mathrm{~kg}$ de peso vivo e uma maior deposição de gordura no intervalo de 25 a $35 \mathrm{~kg}$ de peso vivo, e que a escolha do peso de abate influencia a composição e a qualidade da carcaça, sendo possível oferecer um produto mais atraente ao consumidor e economicamente mais viável ao produtor.

Os coeficientes de alometria para osso, músculo e gordura da perna para machos e fêmeas são apresentados na tabela 4. De acordo com os coeficientes alométricos, o crescimento do osso foi precoce $(b<1)$, nas fêmeas e isométrico $(b=1)$ nos machos evidenciando uma influencia do sexo. O crescimento precoce nas fêmeas também pode ser confirmado por WOOD et al. (1980), ao observarem que o tecido ósseo de fêmeas, apresentam uma maturidade mais precoce. O músculo apresentou coeficientes de alometria iguais a unidade $(b=1)$, independente de sexo, demonstrando que para esses animais, o crescimento do músculo na perna foi semelhante ao crescimento. Estudando o crescimento de cordeiros Santa Inês, SANTOS (1999) verificou que o músculo da perna se desenvolve de modo tardio.

Para gordura os coeficientes de alometria para machos e fêmeas de todos os métodos de alimentação foram diferentes de um $(b>1)$, caracterizando um crescimento heterogônico positivo, ou seja, a gordura da perna desenvolveuse tardiamente em relação ao desenvolvimento da mesma. Resultados semelhantes foram observados por SANTOS (1999), em cordeiros Santa Inês e Bergamácia com coeficiente de alometria para gordura da perna igual a um $(b=1)$. Trabalhando com a mesma linha de pesquisa, GARCIA (2001) estudou o crescimento tecidual da perna em função do corte em cordeiros machos e fêmeas, dos grupos genéticos Santa Inês (SS), Ile de France x Santa Inês (FS), Bergamácia x Santa Inês (BS) e Texel X Santa Inês (TS) abatidos aos 15; 25; 35 e $45 \mathrm{~kg}$. O autor verificou que o osso da perna das fêmeas de todos os grupos genéticos e os machos SS, TS e FS apresentaram coeficientes de alometria diferentes de um $(b<1)$, indicando um desenvolvimento precoce. Nos cordeiros machos do grupo BS o osso apresentou crescimento isogônico $\quad(b=1)$ acompanhando o desenvolvimento do corte e, quando comparou BS com os outros grupos, os

Tabela 4 - Parâmetros estimados das equações de alometria e erro padrão para osso, músculo e gordura da perna em relação ao peso do corte de cordeiros machos $(\mathrm{M})$ e fêmeas (F) submetidos a diferentes métodos de alimentação (M1, M2 e M3) e teste t $(H o: b=1)$.

\begin{tabular}{lllccccc}
\hline Tecidos & $\mathrm{S}$ & $\mathrm{M}$ & $\mathrm{a}$ & $\mathrm{b}$ & $\mathrm{seb}$ & Teste $\mathrm{t}$ & $\mathrm{r}^{2}$ \\
\hline Osso & $\mathrm{M}$ & 1 & $-0,040571$ & 0,792304 & 0,093 & $\mathrm{NS}$ & 91,08 \\
Osso & $\mathrm{F}$ & 1 & 0,623496 & 0,576236 & 0,097 & $*$ & 88,67 \\
Osso & $\mathrm{M}$ & 2 & $-0,069874$ & 0,804298 & 0,088 & $\mathrm{NS}$ & 91,67 \\
Osso & $\mathrm{F}$ & 2 & 0,507879 & 0,623117 & 0,070 & $*-$ & 90,72 \\
Osso & $\mathrm{M}$ & 3 & 0,002611 & 0,784116 & 0,098 & $\mathrm{NS}$ & 88,74 \\
Osso & $\mathrm{F}$ & 3 & 0,475309 & 0,635379 & 0,070 & $*$ & 91,11 \\
Músculo & $\mathrm{M}$ & 1 & $-0,072236$ & 0,962250 & 0,053 & $\mathrm{NS}$ & 97,88 \\
Músculo & $\mathrm{F}$ & 1 & $-0,450989$ & 01,080304 & 0,090 & $\mathrm{NS}$ & 95,36 \\
Músculo & $\mathrm{M}$ & 2 & $-0,250791$ & 1,031989 & 0,026 & $\mathrm{NS}$ & 99,48 \\
Músculo & $\mathrm{F}$ & 2 & $-0,511890$ & 1,105195 & 0,076 & $\mathrm{NS}$ & 96,28 \\
Músculo & $\mathrm{M}$ & 3 & $-0,168946$ & 1,008502 & 0,063 & $\mathrm{NS}$ & 94,57 \\
Músculo & $\mathrm{F}$ & 3 & $-0,304293$ & 1,023327 & 0,086 & $\mathrm{NS}$ & 94,57 \\
Gordura & $\mathrm{M}$ & 1 & $-4,595551$ & 2,126700 & 0,184 & $*$ & 95,69 \\
Gordura & $\mathrm{F}$ & 1 & $-3,904407$ & 1,898369 & 0,159 & $*$ & 97,25 \\
Gordura & $\mathrm{M}$ & 2 & $-3,737738$ & 1,802323 & 0,156 & $*$ & 95,00 \\
Gordura & $\mathrm{F}$ & 2 & $-3,764013$ & 1,839417 & 0,066 & $*$ & 99,36 \\
Gordura & $\mathrm{M}$ & 3 & $-3,977511$ & 1,925461 & 0,204 & $*$ & 92,68 \\
Gordura & $\mathrm{F}$ & 3 & $-4,173548$ & 2,009488 & 0,145 & $*$ & 97,43 \\
\hline
\end{tabular}

M1- Alimentação com silagem de milho para cordeiro + ovelha, com fornecimento de concentrado apenas aos cordeiros na forma de creep feeding do nascimento ao desmame, aos 60 dias de idade, M2- Alimentação com silagem de milho para cordeiro + ovelha, com fornecimento de concentrado apenas aos cordeiros na forma de creep feeding, do nascimento ao desmame aos 45 dias de idade e M3- Alimentação com silagem de milho + concentrado com uma proporção de 70:30 na matéria seca (MS) para o conjunto ovelha mais cordeiro do nascimento ao desmame aos 60 dias de idade; seb = Erro padrão; $*$ = significativo para $(\mathrm{P}=0,05)$; $\mathrm{NS}=$ não significativo para $(\mathrm{P}=0,05) ; \mathrm{r}^{2}=$ Coeficiente de determinação. 
cordeiros machos apresentaram um ritmo de crescimento mais rápido do tecido ósseo, com o crescimento do osso em menor ritmo que o muscular. Para o crescimento do músculo, observou que machos e fêmeas dos grupos SS e FS, obtiveram crescimento do músculo da perna semelhante ao do corte, com coeficientes de alometria iguais a um $(b=1)$. Já os cordeiros machos e fêmeas do grupo BS apresentaram crescimento heterogônico negativo, com desenvolvimento precoce em relação ao desenvolvimento do corte, no entanto os cordeiros do grupo TS apresentando comportamento diferente entre machos e fêmeas, sendo os coeficientes de alometria isotônico $(b=1)$ e heterogênico $(b<1)$ respectivamente. Para crescimento do tecido adiposo, GARCIA (2001) observou que os coeficientes de alometria para machos e fêmeas de todos os grupos foram diferentes de um (b>1), com um crescimento heterogônico positivo, demonstrando um desenvolvimento tardio da gordura. Quando comparou os grupos genéticos, não encontrou diferença para os machos. No entanto, observou diferença nas fêmeas, tendo as TS, seguidas das FS, apresentando um ritmo de crescimento mais intenso, indicando que esses grupos genéticos, provavelmente, atingiram a maturidade para esse corte mais precocemente, principalmente em relação às cordeiras SS.

\section{CONCLUSÕES}

Os músculos do pescoço e da costela apresentam ritmos de crescimento diferenciado, sendo isométrico no pescoço e precoce na costela, com o osso (precoce) e a gordura (tardia) em ambos os cortes. O ritmo de crescimento do osso, músculo e gordura da paleta não são influenciados pelo sexo e peso de abate, sendo o osso de crescimento precoce, o músculo isométrico e a gordura tardia. O crescimento do osso da perna é influenciado pelo sexo, mas o músculo acompanha o desenvolvimento do corte e o tecido adiposo é tardio. Os métodos de alimentação não influenciaram o crescimento dos tecidos nos distintos cortes.

\section{REFERÊNCIAS}

BERG, R.T.; BUTTERFIELD, R.M. New concepts of cattle growth. Sydney : Sydney University, 1976. 240p.

GRAHAM, N. McC. Maintenance and gGrowth. In: WORLD ANIMAL SCIENCE. Sheep and goat production. C. Production-System Approach. Amsterdam : Elsevier, 1982. 200p.

GARCIA, I.F.F. Desempenho, características da carcaça, alometria dos cortes e tecidos e eficiência da energia, em cordeiros Santa Inês e Cruzas com texel, Ile de France e Bergamácia. 2001. 316f. Tese (Doutorado em Zootecnia) - Universidade Federal de Lavras.

HAFEZ, E.S.E. Introducciòn al crecimiento animal. Desarrollo y Nutricion Animal. Zaragoza : Acribia, 1972. Cap.1, 472p

HAMMOND, J. Avances en fisiologia zootecnica. Zaragoza: Acribia, 1959. 200p.

HAMMOND, J. Principios de la explotación animal. Zaragoza : Acribia, 1966. 363p.

HUIDOBRO, F.R.; VILLAPADIERNA, A. Estudios sobre crescimento y desarrolo en corderos de raza Manchega. 1992. 191f. Tesis (Doctoral em veterinaria) - Facultad de Veterinaria, Universidad Complutense.

HUXLEY, J.S. Problems of relative growth. London : Methuen, 1932. 276p.

OWEN, J.B. Sheep production. London : Bailliére Tindall, 1976. 436p.

SAS INSTITUTE. SAS User's guide: statistic. V.2, version 6. 4.ed. Cary/North Carolina, 1996. 300p.

SANTOS, C.L. Estudo do desempenho, das características da carcaça e do crescimento alométrico de cordeiros das raças Santa Inês e Bergamácia. 1999. 142f. Dissertação (Mestrado em Zootecnia) - Universidade Federal de Lavras.

SOBRERO, T. Aspectos poco difundidos de la cria lanar y vacuna. 2.ed. Uruguai : Hemisfério Sul, 1986. V.1, 488p.

TAYLOR et al. Breed and sex differences among equally mature sheep and goats. 5 Lipid in dry tissue. Animal production, v.49, n.3, p.411-422, 1989.

WOOD, J.D. et al. Carcass composition in four sheep breeds: The importance of typo of breed and stage of maturity. Animal production, v.30, n.1, p.135-152, 1980.

WYNN, P C.; THWAITES, C J. The relative growth and development of the carcass tissues of merino and crossbred rams and weathers. Aust J Agric Res, v 32, p 947-956, 1981. 